\title{
HISTÓRIA DA ENFERMAGEM: UM ROTEIRO PARA O ENSINO DAS PRÁTICAS CUIDATIVAS
}

\author{
NURSING'S HISTORY: A SCREENPLAYTO THE TEACHING OF HEALTH \\ CARE PRATICE \\ HISTORIA DE ENFERMERÍA: UN GUIÓN PARA LAENSEÑANZADE LAS \\ PRÁCTICAS DEL CUIDADO
}

\author{
Maria de Fátima Mantovani' \\ Maria de Fátima de Araújo Silveira² \\ Nágela Valadão Cade ${ }^{3}$
}

\begin{abstract}
RESUMO: O trabalho objetiva apresentar um roteiro, na forma de script de um programa jornalistico e de variedades, similar aos televisivos, contextualizando as práticas cuidativas nos diferentes momentos sócio-econômicos e históricos das sociedades, abordando a inserção social do homem com os modos de produção e a interferência destes no cuidado aos enfermos. Analisa, ainda, a concepção de saúde e doença e as relaçōes de poder que envolvem as práticas de cuidar.
\end{abstract}

PALAVRAS-CHAVE: História da Enfermagem, práticas de cuidar, transformaçōes sociais

\section{INTRODUÇĀO}

O objetivo do trabalho é apresentar uma forma alternativa e dinâmica para o ensino da História da Enfermagem, no que se refere ao periodo compreendido entre os primórdios da civilização e a Revolução Industrial, até o surgimento de Florence Nighntgale no cenário da Enfermagem.

Por se tratar de um conteúdo bastante denso, tornando-se, muitas vezes, monótono e cansativo, tanto para o aluno de graduação quanto para o professor, criamos um roteiro, na forma de programa televisivo, que possa contomar essas dificuldades percebidas como cruciais para o entendimento do desenvolvimento da profissão. Como forma de tornar o roteiro mais real e interessante, utilizamos no texto o tempo verbal presente, num desencadear de fatos que cobrem desde a época primitiva até o capitalismo, de modo a "tornar presente" o evento relatado.

Tomamos como eixo norteador os marcos resultantes das grandes transformações sociais, no referido período, como estratégia de recuperar os conteúdos já apreendidos pelo aluno na fase pré-graduação, inserindo neste conhecimento as práticas de cuidar, de forma critica e reflexiva.

\section{CENÁRIO}

Esse script deve ser apresentado em forma de Seminário, numa sala de aula assim

\footnotetext{
'Enfermeira. Profa Assistente do Departamento de Enfermagem da UFPR. Doutoranda do Programa Interunidades da EEUSP/ EERPUSP.

${ }^{2}$ Enfermeira. Profa Adjunto III do Departamento de Enfermagem da UEPB. Doutoranda do Programa Interunidades da EEUSPI EERPUSP

${ }^{3}$ Enfermeira. Profo Assistente do Departamento de Enfermagem da UFES. Doutoranda do Programa Interunidades da EEUSPI EERPUSP.
} 
organizada: 1 mesa, com 3 cadeiras ao centro, na frente. No lado esquerdo da mesa: 1 tela para projeção, 1 projetor de slides e um ambiente separado, montado a partir de um biombo com fundo preto, 2 cadeiras e uma mesa de centro, para a entrevista. No lado oposto da mesa deverão estar 1 televisão, 1 videocassete e 1 aparelho de som, que possam ser controlados pelos repórteres/apresentadores. Em cima da mesa estarão o nome dos repórteres, colocados em pedaços de cartolina montados em forma de pirâmide.

\section{SCRIPT}

O programa é apresentado por 3 repórteres (Repórter 1-R 1, Repórter 2-R-2, Repórter 3 - R3), que são substituídos pelos respectivos nomes dos apresentadores.

\section{R-1. BOATARDE!}

Eu sou R-1 e ao meu lado as jornalistas e repórteres R-2 e R-3.

(Em exposição na tela, 1 slide com o nome do Seminário e, em seguida, 1 foto de 1 mulher cuidando, de preferência, que seja relativa ao periodo. )

R-3. A doença esteve associada ao homem desde o aparecimento da vida sobre a terra, e este tentou lidar com ela da melhor forma possivel. As doenças e os acidentes refletem de várias maneiras o mundo em que se vive, o que se faz nele e com ele, e informam a respeito da dieta, condições de vida e aspectos da classe social e outras características da sociedade. Além da relação entre as doenças e condição econômica e social de dada população, os cuidados e tratamentos também refletem a estrutura de uma sociedade, sua estratificação e divisões de classe (Rosen, 1980).

R-1. Como processo social a doença se origina, muitas vezes, de condições materiais adversas da existência, diretamente vinculadas às relações sociais de trabalho e se reflete também sobre ambas. Essas inter-relações exigem que se estude o problema sobre um prisma amplo, abrangendo tanto quanto possivel suas múltiplas faces.

(Ao fundo, a música Claire de Lune, de Claude Debussy, na tela de projeção um slide contendo a indicação do período).

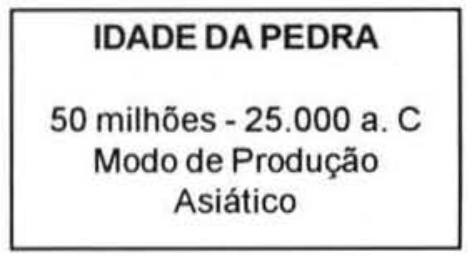

R-1. Mostraremos, agora, imagens realizadas pelos nossos repórteres de cavernas. (Utilizar cenas dos filmes A Guerra do Fogo e 2001 Uma Odisséia no Espaço, que mostrem o homem primitivo descobrindo o fogo, lutando pela subsistência e disputando água e alimentos com outros grupos)

R-2. A nossa forma de propriedade é o modo de produção asiático, nele nós criamos animais e vivemos da caça e da pesca. As práticas de cuidar dos enfermos são instintivas e ligadas a açőes que garantam a nossa sobrevivência (Marx, 1991, Geovanni, 1995).

R-1. Os homens agrupam-se em tribos e tudo que não podem explicar, como no caso das doenças, atribuem a forças sobrenaturais. Dentre as práticas que podemos assistir com nossa visita, as compreendemos como mágico-religiosas, tendo mais uma conotação de religião 
, de sobrenatural e de superstição do que de cura propriamente dita. Vimos rituais de dança e a ingestão de ervas amargas para espantar os demônios causadores de doenças, e a adoração de animais, por eles considerados sagrados, como forma de obterem ajuda das forças naturais (Burns, 1956).

Nossos repórteres de cavernas, observaram desenhos que mostram, dentre outras coisas, a vida desses habitantes, o sofrimento com as enfermidades, com as fraturas nos membros e as infestações parasitárias, e até cenas de parto.

(Cenas do Globo Repórter, exibindo desenhos feitos pelos homens primitivos na paredes das cavernas).

R-1. Após estas imagens os nossos repórteres foram verificar o que os homens estão fazendo para sobreviver e observaram que caçam, pescam e utilizam o que colhem na natureza. R-2, como estão as práticas de cuidar na nossa época?

R-2. Eles agrupam-se em tribos, e tudo que não podem explicar, como doenças, são atribuidas aos espíritos e a forças sobrenaturais. Evocam animais adorados e divinizados pelo homem, com o objetivo de os ajudarem a vencer as forças naturais, como por exemplo: 0 pássaro traz mensagens celestiais e a cobra tem a missão de representar e comunicar a vontade dos mortos. O fato dos povos primitivos pintarem o corpo com tinta colorida e realizarem rituais de dança constituem formas de espantar os demônios. Como forma de tratamento, tentam modificar algo no enfermo para enganar os espiritos ruins que querem prejudicá-lo. Dentre as práticas terapêuticas, usam trocar o nome do doente, colocar máscara no rosto para mudar a fisionomia e revestir com pele ou pêlo de algum animal forte e valente, dar vísceras de animal para ser comida ou colocá-la sobre o corpo do enfermo. Com isso, pretendem que a força e a coragem do animal passe para o enfermo, fortalecendo-o. Os sinais e sintomas apresentados pelos doentes também têm uma conotação mágica. Dentre algumas representações que têm da doença, a hemorragia é considerada a fuga dos demônios, sendo um bom sinal.

Algumas doenças, como a histeria e a epilepsia vêm da concepção de que a alma sai do corpo após a morte e invade outro corpo, tornando-o enfermo. Este tipo de pensamento sobre a doença justifica o comportamento da civilização em cultuarem os mortos.

A terapêutica traduz-se pela ação nestas forças desconhecidas, cabendo aos magos ou feiticeiros intervirem na doença mediante praticas mágico-religiosas. As pessoas que conhecem as estrelas, as plantas e os venenos com a capacidade de vencer os demônios, e as que sabem como evocar os mortos e retirar os demônios do corpo, são exaltados e têm o poder de cura. Acreditam que as envas amargas podem afugentar os espiritos (Geovanni, 1995).

R-1. A coleta de alimentos está se tornando escassa. Os recursos naturais vegetais estão se tornando cada dia mais raros. O que, na sua opinião R-3, o homem vai ter que fazer para sobreviver a partir de agora?

R-3. Nota-se que alguns grupos já estão iniciando a caça sistemática a grandes animais e a migração para novos territórios onde tendem a se estabelecer.

R-2. É verdade que as mulheres estão cuidando da terra e plantando alimentos?

R-3. Sim, as mulheres têm associado o conhecimento sobre o seu ciclo biológico interno para entender os ciclos da natureza. É mais ou menos assim: Quando a terra está molhada pode-se plantar que nasce e quando o tempo está seco é propício para a coleta e não para o plantio. Além do mais, as tribos estão se agrupando e formando cidades, seja por acordo 
entre elas, seja por brigas e conquistas. Os perdedores nestas batalhas tornam-se escravos dos vencedores. A comunidade constituida de camponeses baseia-se no fato de seus membros serem trabalhadores e proprietários da terra, cultivando-a para sua subsistência. Como proprietários começam a defender seus bens materiais de outras tribos (Muraro, 1995, Marx, 1991).

(Na tela, slide com indicação do período)

\begin{tabular}{|c|}
\hline CIVILIZAÇÕES \\
ANTIGAS DO ORIENTE \\
4.500 a.C - Idade Média \\
Modo de Produção \\
Antigo
\end{tabular}

R-1. Muitas civilizações estão surgindo, como as sociedades pré-helênicas, que iniciamse no Oriente 4.500 a 2.000 a C. e constituem-se em Mesopotâmia, Babilônia, Antigo Egito, Assíria, Persa e outras. As mais recentes constituem a civilização clássica: Grécia e Roma, que datam de 600 a 500 a.C., as sociedade helênicas. R-2, como é a questão da saúde nestas civilizações?

R-2. Estas civilizações apresentam características muito distintas e, portanto, não há como generalizar a questão da doença e as práticas relacionadas a ela, R-1, mas podemos considerar, de forma resumida, que nas civilizações antigas a terapêutica é orientada por duas vertentes. A que mais predomina é a concepção da doença como algo influenciado por crenças e por superstições, sendo a prática de cura realizada por magos-sacerdotes nos templos, com conotação mágica e adoração de divindades e deuses. A outra vertente são as práticas de cura que são realizadas pelos médicos e cirurgiões e, apesar das duas distinções, médicos e sacerdotes, ambos compartilham o mesmo local de cura e os conhecimentos sobre doença. Eles já conhecem algumas enfermidades como a tuberculose, o reumatismo e doenças venéreas e a terapêutica mescla a adoração das divindades em seus templos específicos, com o objetivo de ajudá-los a espantar os demônios, e o uso de frutas, flores, ervas, drogas e massagens. A respeito das práticas cuidativas dispensadas aos doentes, temos conhecimento de que em algumas regiões são realizados por escravos, mas em sua maioria, são executados pelas mulheres da família do enfermo, não tendo essas práticas nenhuma especificidade e podendo ser consideradas como uma continuidade das atividades domésticas (Castiglioni, 1941, Burns, 1956, Geovanini, 1995).

R-1. O mundo grego está sofrendo profundas alterações e o progresso da ciência e da filosofia está levando as elites a desviaram-se das velhas crenças

R-2. Já Hipócrates está utilizando o método indutivo enfatizando a importância do diagnóstico, terapêutica e prognóstico. Fator que está causando controvérsia entre seus adeptos. Ele realiza exame e a observação do homem como um todo e a atenção aos sinais e sintomas são o grande destaque dos seus ensinamentos. Ele admite causas naturais (ar, temperatura ambiental, desequilíbrio do corpo) da doença, contrapondo-as às sobrenaturais (Silva, 1986). Para Hipócrates a natureza recupera as forças vitais do doente e assim a terapêutica consiste em ginástica, banho de mar, massagens e dietas especiais.

R-3. As práticas de saúde estão se baseando na experiência e no conhecimento da natureza. As práticas de cura dos gregos são permeadas por um pensamento mitológico como o culto à divindade de Asclépio (429 a C.), deuses e curadores. 
Pode-se dizer que os gregos têm uma medicina desenvolvida. A filosofia grega é um marco importante, o que pode estar associado à abertura do pensamento das castas sacerdotais que tomam-se menos fechadas e susceptiveis à crítica.

Criam-se escolas de medicina e desenvolve-se o pensamento cientifico e estes médicos não sacerdotes são chamados de Asclepiades. Alguns destes viajam, prestando assistência à distância, nas casas, e têm ajudantes para preparar as raizes e, posteriormente, remédios a serem usados pelos enfermos.

A Grécia é o centro cultural do mundo e desenvolve a arte, a filosofia, as ciências biológicas e a medicina.

(Na tela, cena do Templo de Asclepius)

\section{R-2. o que está pegando na moda hoje, R-1?}

R-1. Se você quiser ficar por dentro da moda, vista um modelito desse tipo, proposto pelo nosso editor de moda, ZORBA, o grego.

(Vestuário Grego- exibir um slide com uma mulher ou homem vestido de túnica grega, calçando sandália amarrada nas pernas)

\section{R-2. ROMA URGENTE!}

Os cidadãos romanos foram impedidos de exercer a medicina. Por que isso está ocorrendo, R-3?

R-3. Para os cidadãos romanos as atividades nobres referem-se à prática da agricultura. Eu gostaria de comentar alguns aspectos que envolvem a doença em Roma: a medicina, a cirurgia e os cuidados hospitalares são realizados por escravos migrados da Grécia, onde esta prática é bem desenvolvida. O governo romano tem incentivado esta vinda porque as práticas de saúde neste pais é considerada indigna e pouco aceita pela sociedade, mas devido o grande número de feridos decorrentes das constantes batalhas enfrentadas por este povo guerreiro, tem havido necessidade destes profissionais, para fazerem todo um trabalho de recuperação dos feridos, principalmente agora, que construíram um hospital somente para os militares.

Apesar das práticas de cura desenvolvidas pelos romanos serem inexpressivas, destacam-se por terem um bom sistema de higiene pública e exercerem controle sanitário sobre a população, com leis efetivas sobre sepultamento dos mortos, regras para prostituição, limpeza dos canais e canalização de água potável (Bums, 1956).

R-1. Está chegando aos nossos estúdios a notícia de que os cidadãos romanos estão sofrendo com os altos impostos e com as epidemias que estão fora de controle e assolam o país . Mudanças sérias no modo de produção e atenção à saúde deverão ocorrer. No próximo bloco abordaremos em profundidade esta questão.

(Na tela, slide com indicação do período)

\begin{tabular}{|c|}
\hline IDADE MÉDIA \\
Séc. IV até o Séc. XVI \\
Modo de Produção \\
Feudal
\end{tabular}


R-3. Hoje, ano 313 d.C., Constantino, o Grande declara o Cristianismo como religião oficial. Está inaugurada a Idade Média. ALGO NO AR ACONTECE: muitas mudanças deverão ocorrer, levando a uma fase chamada de Feudalismo. O FEUDALISMO EMPLACA? Se você acha que sim, ligue 0800 - (número do telefone da escola), se você acha que não, ligue 0800

_. Você concorre a um prêmio que seja interessante e divertido, tipo: ... ganhe nota 10 na construção de outro roteiro após o capitalismo). LIGUE DJẢ!

(Música de fundo - Samba pa ti,

Ottmar Liebert)

R-3. À desintegração paulatina do modo de produção antigo, novas relações econômicas se sucedem, dando origem ao feudalismo. Em seu início, a Europa ocidental foi palco de expressivos deslocamentos de população, na esteira das sucessivas incursões bárbaras. Estas acarretaram, simultaneamente ao abandono das terras produtivas pelos pequenos lavradores independentes, a sua concentração nas mãos dos mais poderosos. Consequentemente, em troca da proteção destes últimos, foi introduzida a servidão entre os primeiros (Marx, 1991).

Dentro dessa infra-estrutura que se carateriza por uma decadência econômica generalizada, extinguiram-se as atividades comerciais e industriais, anteriormente existentes. A urbanização do mundo greco-romano arrefeceu ao mesmo tempo em que se fortaleceram as relações agrícolas de produção de base servil. O Cristianismo pós-apostólico completa esse quadro, matizando-o com as tintas da ignorância, superstição e credulidade, emolduradas por um ascetismo mórbido e pelo desprezo à vida terrena. Atualmente, a Igreja cristã organiza-se internamente através da constituição da hierarquia eclesiástica e da definição de dogmas e rituais. O monasticismo, cujas raizes estão no século IV, adquire importância com São Bento, a partir do século VI. As ordens monásticas desempenharam um papel relevante durante toda Idade Média, tanto na esfera cultural (com os copistas garantindo a preservação da cultura helênica) como na da assistência aos pobres e enfermos. Na Europa ocidental, por muitos séculos, os mosteiros têm tido sob seu encargo o asilo e a atenção à saúde das populações circunvizinhas (Almeida Filho, 1988).

A propriedade feudal desenvolve-se sob a influência da estrutura militar germânica. A base dessa formação é novamente a comunidade. No entanto, não como a antiga comunidade, a dos escravos, mas a do pequeno camponês reduzido à servidão. A organização feudal é uma associação dos proprietários armados (nobres) contra uma classe produtiva subjugada, os servos. Estas organizações feudais de propriedade da terra têm sua contrapartida nas cidades sob as formas de propriedade corporativa - a organização feudal dos ofícios. $\mathrm{Ai}$, a propriedade consiste, principalmente, no trabalho de cada pessoa, individualmente (Marx, 1991).

R-2. O Cristianismo, agora como religião oficial, transmite a idéia de a doença ser algo enviado por Deus, para expiação dos pecados e o corpo enfermo é visto como um elo entre a divindade e os homens, com a finalidade de fortalecer o espírito.

Neste contexto, a enfermagem nasce como um serviço organizado, através da instituição do diaconato. Este serviço passa a coexistir, a partir de agora, com a prática exercida (desde sempre) no interior dos lares, em atendimento às necessidades deste ou daquele de seus membros (Geovanini, 1995).

(Na tela de projeção a exposição de uma foto mostrando cenas de religiosas cuidando) 
R-1. Muçulmanos perseguem os cristãos e a Igreja cria expedições militares denominadas Cruzadas, a seu serviço. R-2, qual a influência que se está percebendo das Cruzadas para as práticas de cuidar?

R-2. É com as Cruzadas que está se iniciando a criação de ordens militares de Enfermagem: Cavaleiros de São João, Templários, Teutônicos e Cavaleiros de São Lázaro, com cunho militar-religioso, trabalhando sob as orientações da Igreja. " Nesse momento, além da interferência dos ideais cristãos na profissão, observa-se a construção dos principios de disciplina, ordem e obediência no ato de cuidar" (Bretas, 1994). A partir da Cruzadas, hospitais femininos e masculinos estão se expandindo para a Europa.

(na tela, exposição de imagens de um hospital do periodo)

R-3. "Assim constrói-se a ideologia do cuidado, centrada basicamente nos princípios de submissão , disciplina e abnegação, mediada pelo poder da Igreja e/ou do poder do Estado, sem uma produção sistemática do "saber", e portanto, sem poder". (Bretas, 1994).

R-2. DICA DO DIA: Se você está cansada, com dores no corpo, tome um banho com água e folhas de lima e verá como o seu corpo ficará relaxado. Com esta dica do dia, iniciamos o nosso momento de saúde. Analisarei a situação atual entre medicina e enfermagem . Assistimos, neste momento, a uma separação entre medicina interna, exercida por monges sob o signo da caridade, e a cirurgia que é considerada imprópria para os monges devido ao derramamento de sangue, e fica a cargo de leigos, cirurgiōes- barbeiros que curam feridas, fazem intervenções cirúrgicas e exercem o ofício de barbeiros. Assim, a divisão de trabalho entre estas práticas toma por base o contraste entre o natural e o transcendental, o visivel e o oculto. Do mesmo modo a enfermagem enquadra-se na esfera das atividades eminentemente manuais, realizando tarefas que não exigem preparo e saber especializados. Cuidam dos corpos enfermos ou feridos, do visivel, portanto do desprestigiado (Silva, 1986).

\section{R-1. NOVAS MUDANÇAS NA ORDEM ECONÔMICA}

Em meados do século XIV, a Europa está se tornando um foco de diversas catástrofes como a Peste Negra e a Guerra dos Cem Anos. É um período de fome, pobreza, miséria, escasseamento da população e, consequentemente, queda na produção e no consumo de bens materiais.

A cidade já é um foco importante de comércio, com o incremento dos descobrimentos marítimos ocasionando importantes modificações no setor agrícolas e aumento de bens materiais (Burns, 1956).

(na tela, slide com indicação do período)

$$
\begin{array}{|c|}
\hline \text { CIVILIZAÇÃo } \\
\text { OCIDENTAL MODERNA } \\
1517-1789 \\
\text { Modo de Produção } \\
\text { Burguês/capitalismo }
\end{array}
$$

R-3. O mercantilismo é simplesmente uma teoria econômica mas também uma prática política que consiste em regular os fluxos monetários entre as nações, os fluxos de mercadorias correspondentes e a atividade produtiva da população. A política, mercantilista baseia-se 
essencialmente no aumento da produção e da população ativa com o propósito de estabelecer fluxos comerciais que permitam ao Estado conseguir a maior afluência monetária possivel graças à qual poderá custear a manutenção dos exércitos e todo o aparato que assegure a força real de um Estado com relação aos demais (Luz, 1988).

"A principal rota do comércio deslocou-se do Mediterrâneo para o Atlântico; ocorreu o aperfeiçoamento do sistema de crédito e do sistema bancário, as corporaçöes entraram em declínio: aumentou extraordinariamente o suprimento de metais preciosos oriundos das colônias americanas (...) essa revolução comercial gerou fortunas que formavam o alicerce para a grande expansão industrial dos século XVII e XVIII" ( Hubermam citado por Silva, 1986, p.43)

A partir do aprimoramento do comércio a longa distância e conseqüente aumento das cidades, a população representada por mercadores, artesão, servos, fugitivos, camponeses expulsos das terras, e outros, cresce significativamente, modificando as necessidades de assistência social (Singer, 1981).

R-1. Os nossos repórteres de rua realizaram uma matéria que enfoca como a Igreja tem se organizado para aumentar e consolidar o seu poder. As estratégias utilizadas vão desde o confisco e guarda das obras literárias até à formação dos tribunais de Inquisição, que visam eliminar todas as formas de resistência ao seu poder.

Cenas do Filme O NOME DA ROSA (tentativa frustada de entrar na biblioteca da abadia, posteriormente o diálogo entre o monge e o aprendiz sobre o motivo do confisco de obras literárias pela Igreja).

R-1. Estatisticas aterradoras nos dão conta da queima de mulheres feiticeiras em fogueiras.

R-2. A extensão da caça às bruxas é espantosa. Elas são queimadas vivas na fogueira, na Alemanha, Itália, França e Inglaterra. Estima-se que o número de execuções chegue a 600 por ano, uma média de 3 por dia (exceto aos domingos); Porém, na área de WERTZBER, 400 mulheres foram assassinadas num único dia. No bispado de Trier, 2 aldeias foram deixadas apenas com 2 mulheres cada uma. $85 \%$ das pessoas queimados são constituidas de mulheres (Murarro, 1995).

Nossa câmera escondida registrou momentos da prisão de uma mulher acusada de ser bruxa. As cenas são aterrrorizantes. Pedimos que retirem os menores e as pessoas muito sensiveis da sala.

FILME: O Nome da Rosa (cenas que mostram a prisão de uma mulher acusada de bruxaria após o roubo de uma galinha, seguida do julgamento, condenação e execução).

\author{
ISTO AINDA VAI ACABAR MAL! \\ Porquê tudo isso, R-3?
}

R-3. Desde a mais remota antigüidade, as mulheres são curadoras populares, as parteiras, enfim, detém saber próprio, que lhes é transmitido de geração para geração. Em muitas tribos primitivas são elas as xamãs. Na Idade Média, seu saber se intensifica e aprofunda. A mulheres camponesas pobres não têm como cuidar da saúde, a não ser com outras mulheres tão camponesas e tão pobres quanto elas. Elas (as curadoras) são as cultivadoras ancestrais das ervas que devolvem a saúde, e são também as melhores anatomistas de hoje. São as parteiras que viajam de casa em casa, de aldeia em aldeia, e são também as médicas populares para todas as doenças. Agora, ela estão representando uma ameaça. Em primeiro lugar, ao poder médico, que vem tomando corpo através das universidades no interior do sistema feudal. Em segundo, porque formam organizações pontuais(comunidades) que, ao se juntarem, formam vastas confrarias, as quais trocam entre si os segredos da cura do corpo e muitas vezes da 
alma.

O poder disperso e frouxo do sistema feudal para sobreviver é obrigado, a partir do fim do século XIII, a centralizar, a hierarquizar e a se organizar com métodos politicos e ideológicos mais modernos. A noção de pátria está surgindo... A religião católica contribui de maneira decisiva para essa centralização do poder. E está fazendo isso através dos tribunais da Inquisição que varrem a Europa de norte a sul, leste e oeste, torturando e assassinando em massas aqueles que são julgados heréticos ou bruxos. Este "expurgo" visa dentro de regras de comportamento dominante as massas camponesas submetidas, muitas vezes aos mais ferozes excessos dos seus senhores, expostas à fome, à peste e à guerra e que se rebelam. $E$ principalmente as mulheres.

Assim, a perseguição às bruxas e aos heréticos nada tem de histeria coletiva, mas, ao contrário, é uma perseguição muito bem calculada e planejada pelas classes dominantes, para chegar a maior centralização e poder.

Num mundo teocrático, a transgressão da fé é também transgressão política mais ainda, a transgressão sexual que grassa solta entre as massas populares. "Assim, os inquisidores têm a sabedoria de ligar transgressão sexual à transgressão da fé. $E$, punir as mulheres por tudo isso". As grandes teses que estão permitindo esse expurgo do feminino estão no MALLEUS MALEFICARUM, (Munaro, 1995).

R-1. Está em curso um movimento que os seguidores chamam de Renascimento. O que vem a ser esse movimento e que repercussões está trazendo para a humanidade?

R-2. No bojo das transformações econômicas e sociais, e como consequeências das mesmas, o Renascimento está sendo considerado uma revolução cientifica, com repercussões na literatura, artes plásticas, música, cosmologia, tecnologia e filosofia.

"A importância da compreensão dessa ruptura de visão, e conseqüente reorganização, de mundo é a apreensão da globalização do processo e sua inserção social na profunda transformação das relações feudais, possibilitando o surgimento de novas classes sociais com costumes e ideologias próprios, conflitantes com os vigentes na sociedade medieval, a afirmação econômica e social do capital mercantil, o desenvolvimento de mercado de circulação intemacional, ascensão e domínio político da burguesia comerciante e bancaria que, em lugar da terra e tradição de sangue, valoriza as posses materiais e o dinheiro, troca paulatina do poder da Igreja pelo monarca secular como fundamento e cume da ordem social" ( $L u z, 1988)$.

\section{R-1. BOMBA, BOMBA!!!!! PARAAENFERMAGEM!}

Inicia-se na Alemanha a Reforma Protestante. R-2, você acredita que haverá repercussões da Reforma Protestante e do Renascimento para as práticas cuidativas? Quais?

R-2. Sim, pois na Inglaterra (Anglicanismo) e Alemanha (Luteranismo), já expulsaram as religiosas dos hospitais sem mesmo providenciarem alguém para substitui-las e, assim, fecharam muitos hospitais. Mais de 1000 na Inglaterra estão fechados por Henrique VIII. Os cuidados de saúde passam a ser considerados como função da comunidade, saindo da responsabilidade da Igreja que já vem perdendo seu poder. Houve a necessidade de recrutar apressadamente pessoas para realizar as atividades hospitalares e a remuneração é baixa, gerando a contratação de pessoas de baixo nivel sócioeconômico, sem preparo e sem moral. Tal fato já reflete a idéia da sociedade que o trabalho natural é menos valorizado. Além do mais, as características do trabalho desenvolvido por essas mulheres são uma continuação do trabalho doméstico na qual a mulher é ao mesmo tempo doméstica e mãe.

No que diz respeito à Enfermagem, a transição para o capitalismo está correspondendo, sobretudo na Inglaterra, a um período de obscuridade e decadência. O desinteresse crescente 
pela vida monástica e, em conseqüência, a diminuição no número de monjas, aliado ao movimento pela supressão dos mosteiros (desencadeado pelo Reforma), estão contribuindo para a derrocada do principal sistema organizado de assistência social e assistência à saúde das populações pobres. Esta última deixa, portanto, de ser gratuita, uma prática caritativa, há séculos sob a responsabilidade da Igreja, passando a exigir pagamento e a remunerar, miseravelmente aliás, o pessoal que emprega (Melo,1986, Silva, 1986).

No período de laicização das práticas de cuidar, após o declinio do poder da Igreja e substituição dos religiosos nos hospitais, tem-se uma mudança social entre os agentes que a exercem são descritos como pessoas imorais, bêbadas, prostitutas, ladrões... os agentes de saúde começam a ser remunerados, entretanto, suas qualidades morais formam o esboço necessário para o desenvolvimento do preconceito da profissão. (Brêtas, 1994).

R-1. R-3, coloque-nos a par do nascimento do capitalismo, pois R-2 comentou sobre a questão da saúde e gostariamos que esclarecesse este aspecto.

R-3. "Do ponto de vista econômico ocorreram importantes transformações na segunda fase da Idade Média, principalmente a partir do século XI. O ressurgimento do comércio com o Oriente favoreceu o desenvolvimento de algumas cidades (Veneza, Gênova, Palermo, Piza, Paris), onde se constituíram corporaçōes de mercadores e artífices. Essas mudanças deslocaram o eixo econômico da sociedade feudal européia estudada do campo para a urbe; em outras palavras, o setor mais importante da economia deixou de ser a agricultura centrada na herdade senhorial. Em síntese, o restabelecimento do comércio com o Oriente Próximo, a expansão urbana, as Cruzadas, a Peste Negra, o processo de emancipação dos serviços (resultante da conjunção daqueles fatores, aliados ao fortalecimento de monarquias nacionais (Inglaterra e França) provocaram o declinio do feudalismo e o desabrochar de uma nova ordem sócio-políticoeconômica...

Paralelamente, na Idade Média, os cidadãos de cada cidade eram obrigados a se unir contra a nobreza proprietária da terra, para preservar a própria pele. A ampliação do comércio, o estabelecimento de comunicações levou cidades isoladas a conhecer outras cidades, que tinham afirmado os mesmos interesses na luta contra idêntico antagonista. Das muitas corporações de habitantes de burgos nasceu, gradualmente a classe dos burgueses. Os burgueses tinham criado as condições na medida em que se libertavam os laços feudais, e eram criados por elas na medida em que eram determinadas por seu antagonismo ao sistema feudal que encontraram em vigor. Quando as cidades começaram a estabelecer associações estas condições comuns evoluiram para condições de classe, as mesmas classes, o mesmo antagonismo, os mesmos interesses, necessariamente, geraram costumes semelhantes por toda a parte" (Marx, 1991). Com o aumento do comércio e os intercâmbios entre as cidades tem início a acumulação desse capital na mão dos burgueses.

R-1. Foi inventada a máquina a vapor - Começa a Revolução Industrial Inaugurada a primeira organização hospitalar na Europa para atender militares. R-2, você esteve lá, cobrindo a matéria? Nos fale do que observou.

R-2. A formação profissional dos homens ligados a defesa da nação passa a ter um custo para o Estado. O fuzil é introduzido no exército, fazendo-se necessário o treinamento e a seleção dos soldado, pois, a ocupação da nova função exige habilidades cognitivas e técnicas. $O$ investimento financeiro no exército e nos soldados aumenta as expectativas do Estado à produção desses homens, e suas vidas devem ser mantidas em boas condições físicas e de saúde, para que haja retomo do dinheiro empregado. Dessa forma, o aumento do custo nos serviços estatais, o contrabando, e a desordem no meio hospitalar que já existia, constituem os principais motivos econômicos que justificam o início da reforma nos hospitais pelas 
instituições do exército e da marinha.

R-3. Temos notado que as concepções de saúde, e consequentemente, como se conformam as práticas de cuidar, têm se modificado ao longo dos tempos. Para abordar a compreensäo de doença e, portanto, as práticas de cura, precisamos nos reportar as interpretações que vêm sendo formuladas no campo da nossa história, uma vez que a uma nova visão de enfermidade, correspondem alterações na terapêutica, ressaltando que, assim como os modos de produção, essas concepções coexistem e não têm um desenvolvimento linear. No atual contexto da urbanização e consolidação do sistema fabril, surge com força crescente a concepção de causação social da doença, e tem se estabelecido uma relação entre as condições de vida e de trabalho. "...É na condição de vida e trabalho do homem que as causas das doenças deverão ser buscadas" (Engels, 1985) .

Com o capitalismo, surge um quadro nosológico novo, onde predominam as doenças infecto-contagiosas e acidentes de trabalho que, devido a alta incidência, está ameaçando determinados setores da indústria. Nesse modo de produção, a medicina liberal apresenta-se como instrumento de manutenção e reprodução da força-de- trabalho. A saúde/ doença tornase, então, fonte de lucro, produzindo e realizando mais-valia, dando origem à medicalização do hospital, dotando a medicina de um poder autoritário com funções normalizadoras que vão além da existência das enfermidades e da demanda do enfermo ( Almeida Filho, 1988, Silva, 1986).

Cenas do filme GERMINAL ( chegada do trabalhador na mina de carvão, saída para o trabalho dos adultos e crianças, organização dos trabalhadores para enfrentar a opressão).

(Nesse momento, um dos repórteres (R-1) vai para trás do biombo que se encontra ao lado da mesa, põe uma barba postiça, veste um paletó e pega um charuto, para representar Engels, no lançamento do Livro

R-3. Estamos recebendo em nossos estúdios a presença de Friederich Engels, que está lançando o livro "A situação da classe trabalhadora na Inglaterra", e concederá uma entrevista a R2

R-2. Boa Tarde, Mr. Engels. É um prazer recebê-lo nesta tarde de verão de 1845. R-1 Engels - Boa Tarde, Miss.

\section{R-2. Gostariamos de saber porque decidiu escrever "A classe trabalhadora na Inglaterra"?}

Engels - Inicialmente, quero dizer que o assunto abordado neste livro deveria ser um capitulo de um trabalho maior que faria sobre a história social da Inglaterra, mas devido a sua importância obriguei-me a dedicar-Ihe um estudo particular. Durante 21 meses, tive a ocasião de conhecer o proletariado inglês, estudar de perto os seus esforços, os seus sofrimentos e suas alegrias, convivendo com ele ao mesmo tempo que completava estas observações utilizando as fontes autênticas indispensáveis. A Inglaterra foi escolhida porque condições de vida do proletariado em sua forma clássica só existem aqui, e conhecê-las é importante para a Alemanha, pois se as condições de vida do proletariado alemão não chegaram a este ponto, possuem todas as condições para tal, e devem provocar, com o tempo, os mesmos resultados. Quero informar que utilizei nesta obra apenas o que vi, ouvi, e li.

R-2 O senhor poderia nos descrever o que viu nestes 21 meses?

Engels - Os bairros onde se concentram a classe operária são os bairros de má reputação, as ruas não são planas nem pavimentadas; são sujas, cheias de detritos vegetais e animais , sem esgotos nem canais de escoamento, mas semeadas de charcos estagnados e fétidos. A ventilação torna-se dificil pela má e confusa construção de todo o bairro, e como lá vivem 
muitas pessoas num pequeno espaço é fácil imaginar o ar que se respira nestes bairros operários. As casas são tão sujas no exterior como no interior e tem um tal aspecto que ninguém desejaria habitá-las. Nas habitações, nos corredores e vielas transversais, a sujeira e a ruína ultrapassam a imaginação. Ai habitam os mais pobres dos pobres, os trabalhadores mais mal pagos, com os ladrões, os escroques, e as vítimas da prostituição, todos misturados. Também vi, e creio serem estes importantes para a platéia que nos ouve, que em Liverpool, de 45000 habitantes, um quinto deles habitam em porões escuros e mal arejados. Em Bristol, 2800 famílias não possuem um único quarto. Há por volta de 50000 pessoas que não tem onde dormir à noite.

\section{R-2 E quanto à saúde, que aspectos o Sr. observou?}

Engels - Frente às condições de vida que Ihes descrevi, como é possível que a classe operária goze de boa saúde ? Que outra coisa podemos esperar além de uma enorme mortalidade, epidemias permanentes e um enfraquecimento progressivo e inelutável da população trabalhadora? Vejamos os fatos:

* as doenças pulmonares são conseqüência das condições de habitação, assim como o tifo e a escarlatina. Os trabalhadores são atendidos em hospitais onde lhes é administrado vinho, conhaque, preparações amoniacais e outros estimulantes devido ao estado de fraqueza em que se encontram. A mortalidade é alta, mas quando lembramos das condições de vida dos trabalhadores, quando pensamos que as suas casas estão comprimidas e cada canto literalmente abandonado de pessoas, quando pensamos que doentes e pessoas sãs dormem num único e mesmo quarto, numa única e mesma cama, ficamos surpreendidos que uma doença tão contagiosa como o tifo não se propague mais; e quando pensamos nos escassos meios médicos que existem para cuidar dos doentes, quando vemos que pessoas são abandonadas sem nenhum cuidado e ignoram as regras mais elementares da dietética, a mortalidade ainda nos parece ainda mais baixa.

* Existem outras doenças cuja causa direta é a alimentação mais do que a habitação dos trabalhadores; a indigesta alimentação dos operários é totalmente imprópria para as crianças e, contudo, os operários não têm tempo nem meios para proporcionar aos filhos alimentação mais conveniente. Há, ainda, o hábito muito divulgado de dar aguardente aos filhos, ou até ópio, que contribuem para provocar as mais diversas doenças que deixam marcas para o resto da vida. Além da fome, o frio, a bebida é quase epidêmica, o alcoolismo deixou de ser um vício daquele que 0 adquire, torna-se um fenômeno natural, uma consequência necessária e inelutável de condições dadas que agem sobre o objeto. A assistência médica, quando não oferecida por hospitais públicos, é cara e os trabalhadores recorrem a charlatães ou a remédios caseiros baratos que, a longo prazo, só os podem prejudicar.

* O consumo de medicamentos é alto e algumas mulheres que trabalham a domicilio tomam conta de seus filhos ou dos filhos dos outros, administrando-Ihes chás à base de ópio, para as crianças se manterem tranqüilas e se fortalecerem. (Enge/s, 1985).

- Há muitos outras coisas que gostaria de abordar, como o alto número de óbitos abaixo dos 5 anos, e após a instalação das fábricas, a concentração das mortes até os quarenta e nove anos, o envelhecimento precoce entre os mineiros, os baixos salários... Mas pararei por aqui senão falaria a tarde toda. Quem desejar saber mais, compre o meu livro e terá informações mais detalhadas.

R-2 Muito Obrigada, Mr. Engels pela entrevista. Sucesso com o livro!

Engels - obrigado a vocês pela gentileza de divulgarem o meu trabalho.

(Na tela, cenas da situação urbana

caótica na Inglaterra) 
Antes da volta ao cenário do programa colocar a música "Funeral de um lavrador", de Chico Buarque de Holanda, enquanto o repórter R-1 troca de roupa e volta ao cenário.

R-2. É, os trabalhadores estão se organizando.

R-3. A política expansionista da Inglaterra, desencadeou mais uma guerra na Criméia. Os soldados feridos estão morrendo em virtude de altas taxas de infecção. A Inglaterra necessita tomar medidas urgentes para reverter este quadro, recuperando os soldados para as frentes de batalha e vencer a guerra. Há rumores na imprensa de que a má administração e a negligência para com os enfermos têm sido determinantes para que isso ocorra. Não apenas as familias mas também o governo estão preocupados e ansiosos com esses fatos, pois coloca em risco o prestígio e, principalmente, a segurança econômica da Inglaterra. (Gomes et al., 1997).

R-1. NOTÍCIAS DE ÚLTIMA HORA: está chegando a nossa redação a notícia de que foi designada superintendente das Instituições de Enfermagem Feminina dos Hospitais Ingleses na Turquia, Florence Nightingale. Ela chegou aos hospital de Scutari hoje, 5 de novembro de 1854 , com 38 enfermeiras.

(na tela de projeção uma "foto"de Florence)

VOCÊAJUDAAFAZER O NOSSO PRÖXIMO PROGRAMA.

LIGUE E DÊ SUA OPINIÃO. Você também pode enviar fax e/ou e-mail que conseguirão chegar a essa redação em 143 anos, após a criação da temivel INTERNET.

\section{R-2. Florence conseguirá reverter o quadro de mortalidade dos soldados ingleses?}

\section{R-3. Que repercussões para as práticas de cuidado isso pode trazer?}

R-1. Para discutir esse e outros assuntos, na próxima semana estarão outras especialistas para continuar essa história.

Estiveram com vocês, R-1, R-2 e R-3.

BOATARDE!

ABSTRACT: The objective of this work is to present a screenplay, similar to a script for TV shows or TV news programs, in order to put into context the different care practices in different social-economical and historical periods of the societies. Human beings' social insertion and relation established with the means of production and their interference in the health care were analyzed, as well as the conceptions of sickness and health, and the relationships of domination that affect the health care practices.

KEYWORDS: the history of nursing, health care practices, social changes

RESUMEN: El trabajo objetiva presentar un guión como si fuera un programa periodistico y de variedades, similar a los televisivos, para contextualizar las prácticas del cuidado en los diferentes momentos socio-económicos e históricos de las sociedades, en donde se abarca la inserción social del hombre con los modos de producción y la interferencia de estos en el cuidado de los pacientes. Analiza, aún, la concepción de la salud y enfermedad y las relaciones de poder que involucran las prácticas del cuidado.

PALABRAS CLAVE: historia de enfermeria, prácticas del cuidado, transformaciones sociales 


\section{REFERÊNCIAS BIBLIOGRÁFICAS}

ALMEIDA FILHO, N. Bases históricas da epidemiologia. In: ROUQUAYROL, M. Z. Epidemiologia e saúde. 3 ed. Rio de Janeiro: MEDSI, 1988.

BRÉTAS, A . P. As enfermeiras, o poder, a história: um estudo exploratório sobre mentalidades. Campinas, 1994. 92 p. Dissertaçăo (Mestrado - Ciências sociais aplicadas à educação). Universidade Estadual de Campinas.

BURNS, E. M. História da civilização ocidental. Rio de Janeiro: Cultura Geral, 1956.

CASTIGLIONI, A . Historia de la medicina. Barcelona: Salvat, 1941

ENGELS, F. A situaçăo da classe trabalhadora na Inglaterra. São Paulo: Global, 1985.

GEOVANINI, T. et al. História da Enfermagem: versões e interpretações. Rio de janeiro: Revinter, 1995.

GOMES, E.L.R., et al. Dimensão histórica da gênese e incorporação do saber administrativo na enfermagem. In: ALMEIDA, M.C.P.; ROCHA, S.M. (Org.) O trabalho de enfermagem. São Paulo: Cortez, 1997.

LUZ, M. T. Natural, racional, social: razăo médica e racionalidade cientifica moderna. Rio de Janeiro: Campus, 1988.

MARX, K. Formaçōes econômicas pré- capitalistas. Rio de janeiro: Paz e Terra, 1991.

MELO, C. Divisão social do trabalho e Enfermagem. São Paulo: Cortez, 1986.

MURARO, R.M. Breve introdução histórica. In: KRAMER, H.; SPRENGER, J. O martelo das feiticeiras. 11. ed. Rio de Janeiro: Rosa dos Tempos, 1995.

ROSEN, G. Da politica médica à medicina social. Rio de Janeiro: Graal, 1980.

SILVA, G. B. Enfermagem profissional: análise critica. Săo Paulo: Cortez,1986.

SINGER, P. Prevenir e curar: o controle social através dos serviços de saúde. Rio de Janeiro: ForenseUniversitária, 1981.

\section{VIDEOGRAFIA:}

ANNAUD, Jean-Jacques. A guerra do Fogo., CBS FOX, 1976, 1 fita cassete. $100 \mathrm{~min}$.

ANNAUD, Jean-Jacques. O nome da rosa., 1986. 1 fita cassete. $130 \mathrm{~min}$.

BERRI, Claude. Germinal. Cannes, Home Video, 1994. 1 fita cassete. $155 \mathrm{~min}$.

KUBRICK, Stanley. 2001 Uma Odisséia no Espaço. USA, MGM Home Video, 1986. 1 fita cassete. $139 \mathrm{Min}$.

\section{DISCOGRAFIA:}

BUARQUE, Chico. Funeral de um lavrador (2:27 min). Não vai passar. Vol. 2. RGE, 1992.

DEBUSSY, Claude. Claire de lune (10:35 min). The greatest classical hists - Claude Debussy. Movie Play, 1993.

LIEBERT, Ottmar. Samba pa ti. Solo pa ti. Sony Music, s.d. 